\title{
Performance Assessment Techniques for the 3-Phase IAG
}

\author{
Shakuntla Boora
}

\begin{abstract}
This manuscript covers the analytical and optimization based techniques for the performance assessment of 3-phase IAG furnishing 3-phase and 1-phase load. It examines initially the basic phenomenon of voltage build-up and then the steady state performance of 3-phase IAG furnishing 3-phase and 1-phase load. This preliminary study forms the foundation or basis of the design of future controllers. The conventional techniques and MATLAB based optimization technique fsolve is elaborated in detail along-with advantages and disadvantages for attaining the solution of simultaneous non linear equation. The fsolve technique is recommended for the solution of non-linear equations due to its advantages over conventional method.
\end{abstract}

Keywords: IAG, steady-state condition, transient state condition, Numerical techniques, MATLAB, fsolve technique, Optimisation.

\section{INTRODUCTION}

If the stator of an asynchronous machine is energised or excited by an ac system, a rotating nature magnetic field revolving at synchronous speed is established in the air-gap. This rotating magnetic field induces a voltage in the stator as well as rotor winding. The current will flow if the rotor circuit is closed. The rotor attains a speed lower than the speed of the rotating nature magnetic field. The relative speed of the rotating field is positive and hence the slip value is positive and the asynchronous machine works as an asynchronous motor.

The same asynchronous machine can be operated as a generator. There are two basic conditions which should be met: presence of residual magnetism and capacitor bank to furnish reactive power. The asynchronous machine is mechanically rotated at a speed higher than the synchronous speed with the aid of prime-mover. Now the difference between the speed of the rotor and rotating field is negative and hence slip is negative. Now the asynchronous machine starts operating as a generator. It starts feeding power to the grid and acts as a source of supply for feeding 3-phase or 1-phase loads. The shaft torque is conveyed to the stator via air-gap. The net available power at output depends on the value of slip, s. The asynchronous generators are categorised as an isolated asynchronous generator (IAG) as these generators operates independent of grid or infinite bus-bar and is depicted in Fig. 1 The voltage and frequency

Revised Manuscript Received on December 30, 2019.

* Correspondence Author

Dr. Shakuntla Boora*, Electrical Engg. Department, JCBUST, YMCA, Faridabad, Haryana. Email: shaku_boora@yahoo.com

(c) The Authors. Published by Blue Eyes Intelligence Engineering and Sciences Publication (BEIESP). This is an open access article under the CC BY-NC-ND license (http://creativecommons.org/licenses/by-nc-nd/4.0/) parameters of these generators are not fixed and known. Moreover, the voltage and frequency are also affected by the value of excitation capacitor, load, machine parameters and speed of the prime-mover. Also, the magnetizing reactance varies with the operating point even at fixed rotor speed. Therefore the performance assessment of IAG furnishing 3-phase and 1-phase load under steady state and transient conditions is requisite from practical application point of view [1-46].

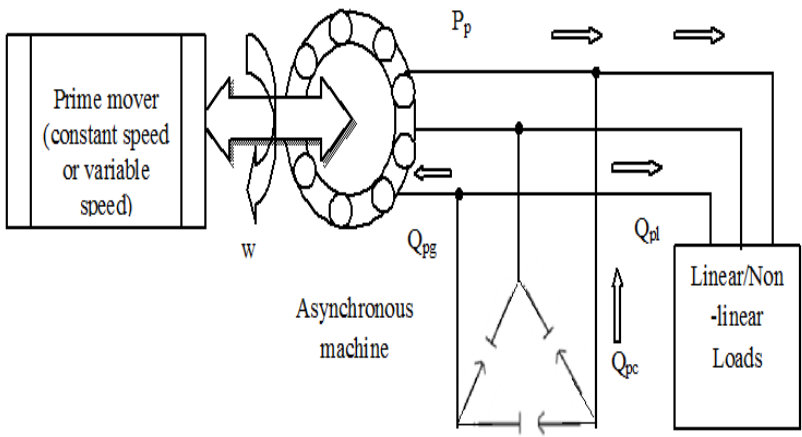

$$
\begin{gathered}
\text { Delta/star } \\
\text { connected } \\
\text { capacitor bank }
\end{gathered}
$$

Fig. 1 Schematic diagram of isolated asynchronous generator (IAG)

The concept of how an induction machine operates as an induction generator in grid isolated mode is described. It is shown that the performance characteristics of IG are slightly different from the induction machine. The performance of IG attained using both theoretical concepts and test results are found quite satisfactorily and are in close resemblance with each other. Use of saturable reactors is discussed here to achieve better voltage regulation. For attaining the voltage regulation more precisely, the use of magnetic amplifiers is recommended. The main disadvantage of IG with only excitation capacitor is of overload and short circuit situation. It is shown that IG is a viable option for brushless based electrical power generation [1]. The two person's i.e Surendra Mathema (Nepal Engineer) and his colleague Akkal Man Nakarmi fabricated small hydro turbines in Kathmandu. They tried to curtail the cost of micro-hydro based electric plants. They manufactured and installed such plants in remote areas. It is discussed that they built around 30 micro-hydro sets in Nepal only. They used asynchronous generators instead of synchronous generators because of its low cost. But the main problem with IG was poor voltage regulation under varying load conditions. So, they designed and installed an electronic load controller in Nepal which allows a voltage variation within $\pm 10 \%$ [2]

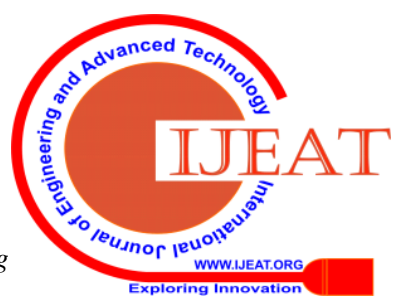




\section{Performance Assessment Techniques for the 3-Phase IAG}

\section{EXISTING TECHNIQUES AVAILABLE}

\section{A. Performance Assessment Techniques for the 3-Phase IAG furnishing 3-phase load}

A tremendous number of research papers examined the performance characteristics of IAG based on equivalent circuit using KVL technique in the loop [1-12]. The performance assessment of IAG under the steady state and transient conditions are also investigated using admittance method [13-20].

A Newton Raphson method of analytically determining the values of $\mathrm{X}_{\mathrm{m}}$ (magnetising reactance) and $\mathrm{F}$ (frequency) for analysing the performance of three- phase type SEIG corresponding to steady state is elaborated. The effect of varying various parameters on the steady state performance are studied or analysed. This study provided the guidelines for the proper design of such systems. The results obtained from analytical and experimental study showed good degree of correlation and testified the feasibility of the proposed method [4].

The SEIG output voltage and frequency depend on various factors i.e. speed, terminal capacitance and load. These factors have imposed certain constraints on its performance. In this paper, the performance assessment of 3-phase SEIG is carried out under different operating conditions i.e. controlled speed, excitation capacitance reactance and load. The proposed scheme helped in selecting the optimum values of speed, excitation capacitance and load for obtaining maximum power output [5].

The performance assessment of SEIG feeding balanced R-L load under steady state conditions is reported. During performance assessment, machine core losses are included. The value of excitation capacitance is estimated under no load and load conditions in order to maintain self-excitation phenomenon and terminal voltage. Few analytical outcomes are verified experimentally and a good correlation is noticed [6].

For performance assessment, the values of frequency $F$ and excitation reactance $X_{c}$ are analytically obtained using Newton Raphson method. An analytical procedure is described to evaluate the number of switching capacitors needed to support the terminal voltage at the desired level and to load the generator upto its rated capacity. The proposed scheme of voltage regulation and the analytical results are validated experimentally on a $3.7 \mathrm{~kW}$ asynchronous machine [7].

A novel method for accessing the performance of 3-phase SEIG subjected to different operating conditions is explored. The values of $\mathrm{X}_{\mathrm{m}}$ and $\mathrm{F}$ for performance assessment purpose are obtained using 'fsolve' routine of MATLAB. In addition to no-load and load characteristics of generator, the performance characteristics relating to fixed terminal voltage and stator current are obtained. Some of the performance characteristics analytically attained are verified experimentally on an induction machine of $1.5 \mathrm{~kW}$ and both results are closely related [8].

The performance assessment of 3-phase SEIG ( $Y$ or $\Delta$-connected) excited by one capacitor and furnishing a single phase load is discussed. The effect of excitation capacitance $\mathrm{C}$ on the various performance characteristics is discussed. The values of $\mathrm{F}$ and $\mathrm{X}_{\mathrm{m}}$ for assessing performance are evaluated using Newton Raphson method. The analytical findings are verified experimentally [9].

A method of evaluating the value of $X_{c}$ for initiating the voltage rise phenomenon at no load for grid isolated operation of 3-phase SEIG is discussed. The proposed scheme is based on the phenomenon of $\mathrm{L}-\mathrm{C}$ resonance and non-linear magnetization characteristics of SEIG. The voltage build up phenomenon under transient condition is also reported in this paper. Analytical results obtained from the proposed scheme are validated through experiments on a $1.5 \mathrm{~kW}$ rating asynchronous machine [10].

The theory of symmetrical components for the performance assessment of 3-phase SEIG furnishing three-phase unbalanced and 1-phase load is discussed. The performance assessment technique is little bit complicated due to effect of unbalance in operating conditions and magnetic saturation. This paper helped in designing a capacitor for a given motor rating. The performance characteristics of SEIG feeding unbalanced load is analysed both analytically and experimentally on a $7.5 \mathrm{~kW}$ machine. The close resemblance between the analytical and experimental outcomes validates the considered scheme [11].

The performance assessment of SEIG (3-phase) connected in parallel and feeding a balanced load is discussed [12]. A Newton Raphson method is considered for obtaining the values of $\mathrm{F}$ and $\mathrm{X}_{\mathrm{m}}$ for the performance assessment of SEIG corresponding to steady state. The performance characteristics are strongly affected by the various parameters of machine, excitation capacitance, speed, and load nature and magnetizing characteristics. The analytical outcome obtained using the proposed schemes are validated experimentally. The two techniques of controlling common bus voltage control for any number of SEIG's operating in parallel under balanced steady state conditions is emphasized [13]. The control of voltage is provided by capacitance $C$ and machine speeds. The proposed scheme may be suggested for a single SEIG or a number of SEIG's of same or different ratings operating at equal or different speeds. The effects of various electrical parameters on the voltage control are reported for a number of SEIG's operating in parallel. The theoretical investigations made from the two techniques are verified experimentally. The various conditions for the self-excitation phenomenon for various types of generator and load connections with the application of theory of symmetrical component and sequence circuit models are derived [14]. The performance assessment techniques for 3-phase SEIG supplying balanced/ unbalanced loads with balanced and unbalanced excitation schemes is discussed . The theoretical investigations made from the proposed models are verified experimentally under different balanced and unbalanced operating conditions. A Newton Raphson method to evaluate the values of $\mathrm{X}_{\mathrm{m}}$ and $\mathrm{F}$ for deriving the performance related equations of SEIG furnishing balanced load is promoted [15]. The effects of $X_{c}$ on the different performance characteristics related with SEIG are analysed. The conditions for the existence of self-excitation in terms of capacitance, speed and load impedance are explained.

ublished By: 
The performance assessment of SEIG using a single capacitor configuration is investigated [16]. The two non linear nature equations containing $\mathrm{F}$ and $\mathrm{X}_{\mathrm{m}}$ are formed using the application of symmetrical component theory in the circuit model of SEIG. The values of $F$ and $X_{m}$ for the performance assessment are obtained using Newton Raphson method. The analytical calculations are verified experimentally. The close resemblance between both results proved that a 3-phase SEIG could be satisfactorily excited by a single capacitor.

A new approach to analyse the performance of SEIG subjected to different operating conditions under steady state is introduced [17]. A Node based approach is applied in the equivalent circuit of SEIG to access the values of slip s and the magnetizing reactance $X_{m}$ for the complete performance assessment of SEIG. The analytical results are verified experimentally.

An iterative method based performance assessment of SEIG corresponding to steady state is described [18]. A Nodal admittances method is applied across the air-gap node to obtain the values of $\mathrm{X}_{\mathrm{m}}$ and $\mathrm{F}$ for the performance assessment corresponding to steady state. The proposed scheme made the problem formulation into simple algebraic calculations. Both the rate of convergence and accuracy are shown to be rapid and accurate. Effect of core loss is included. The performance assessment of the SEIG with long shunt and short shunt compensation are carried out. The computed results are verified experimentally on a $2 \mathrm{~kW}$ induction machine.

An improved iterative technique to evaluate the values of $\mathrm{F}$ and $\mathrm{X}_{\mathrm{m}}$ for the performance assessment of SEIG corresponding to steady state is implemented [19]. The final values of $\mathrm{F}$ and $\mathrm{X}_{\mathrm{m}}$ are obtained in just 4 to 5 iterations only. Using the proposed scheme, the performance of SEIG is carried out under different operating conditions. The theoretical and experimental outcomes close association confirmed the validity and applicability of the betrothed scheme.

The optimization technique of evaluating the values of $F$ and $\mathrm{X}_{\mathrm{m}}$ for the performance assessment of SEIG corresponding to steady state is focussed [20]. The two MATLAB inbuilt functions "fmin" and "constr" are employed to simplify the total impedance of the equivalent circuit (per-phase) to evaluate the values of $F$ and $X_{m}$ for the performance assessment purpose. The theoretical and experimental results are shown to be closely related.

A GA based control technique for attaining voltage and frequency regulation of the SEIG is introduced [21]. The optimized values of these control variables are attained by evaluating the performance index. Using these optimized values of the control variable, the desired performance of the SEIG under steady state conditions is obtained. GA modelling based analytical results of the SEIG is validated experimentally. The close resemblance between the two results proved the validity of the proposed scheme.

The performance assessment of 1-phase SEIG feeding a resistive nature load is emphasized [22]. Application of nodal admittance method in the equivalent circuit yielded the value of $\mathrm{F}$ and $\mathrm{X}_{\mathrm{m}}$. A conventional Newton Raphson (N-R) method is discussed for evaluating the values of $F$ and $X_{m}$ for the performance assessment purpose of SEIG. Experiments are performed to verify the theoretical predictions. This paper also provided the guidelines on how to select the proper value of excitation capacitance in order to attain optimum utilization and better performance of the machine.

The performance assessment of 3-phase SEIG rotated by both regulated and unregulated turbines is envisaged [23]. The desired values of $\mathrm{F}$ and $\mathrm{X}_{\mathrm{m}}$ are accomplished on equating the total admittance of the circuit to zero. For regulated turbines, two modes i.e. constant speed and frequency operation are analysed. For constant speed mode, the value of $\mathrm{F}$ is evaluated using a simple iterative algorithm. For constant frequency mode, the value of p.u. speed is evaluated by a quadratic equation solution. For unregulated turbine, a two-level iteration technique is adopted to evaluate the values of torque and speed. Secant method is included for fast convergence and for providing additional iteration.

A method of evaluating the squirrel cage IG output voltage and its frequency when subjected to resistive load under steady state is discussed [24]. The SCIG output voltage and its frequency are varied for a wide range of speeds. The operating slip remained small during the performance assessment and hence made the system efficient. The analytical outcomes are verified experimentally.

The symmetrical component theory based performance assessment of a 3-phase SEIG furnishing unbalanced load particularly 1-phase load is covered [25]. A C-2C excitation scheme is opted for furnishing a 1-phase load in order to obtain maximum power output of a machine and to make the system balanced. An optimization technique is used for evaluating the values of $\mathrm{F}$ and $\mathrm{X}_{\mathrm{m}}$ for carrying out performance assessment. The proposed scheme also helped in calculating the derating factor and voltage regulation under unbalanced conditions. Analytical outcomes are validated experimentally.

The eigen values based transient performance of the SEIG furnishing dynamic load (IM) using short and long shunt connections is presented [26]. The effect of both types of connections on the voltage variation and dynamic performance of SEIG with or without dynamic load is carried out. The analytical results are validated experimentally using a $1.1 \mathrm{~kW}$ induction machine.

\section{PERFORMANCE ASSESSMENT OF IAG FEEDING BALANCED/UNBALANCED LOAD}

\section{A. Performance Assessment of 3-Phase IAG Feeding 3-Phase Load [27]}

The performance assessment techniques of IAG furnishing 3-phase or 1-phase load provides basis for designing various control strategies for IAG. Hence, the performance assessment aspect is requisite for designing the controllers. Many scientists and researchers have evaluated the steady state based performance of 3-phase Isolated Asynchronous Generator (IAG) feeding three-phase load using equivalent circuit [1-20] depicted in Fig. 2

The steady state performance characteristics of 3-phase IAG or SCSIG feeding 3-phase resistive load are presented [27]. 


\section{Performance Assessment Techniques for the 3-Phase IAG}

For steady state performance assessment, the values of frequency $\mathrm{F}$ and magnetising reactance $\mathrm{Xm}$ are attained using a MATLAB based optimisation technique fsolve. With the known values of $\mathrm{F}, \mathrm{Xm}$ and $\mathrm{Vg}$ the complete performance of the SCSIG can be obtained from the equivalent circuit. The effect of excitation capacitance on the different performance characteristics under no load and resistive load of SCSIG is illustrated. The experimental result outcomes are investigated on laboratory available induction machine set of $3.73 \mathrm{~kW}$ coupled with a dc shunt machine (prime-mover).

\section{A. Performance Assessment Technique}

The equivalent circuit of an IAG comprises of stator winding (represented by stator resistance and reactance), rotor winding (represented by rotor resistance and reactance), resistive load and an excitation capacitance depicted in Fig.1. The laboratory hardware set up is shown in Fig. 3 and the capacitor bank for IAG is shown in Fig. 4 .

All the parameters of the equivalent circuit are regarded as constant and only the parameter magnetizing reactance Xmg is considered to be effected by the magnetic saturation [33]. KVL application in loop shown in Fig. 2 results into the formation of the following equations:

$$
\mathrm{Z}_{\mathrm{st}} \mathrm{I}_{\mathrm{st}}=0
$$

For the operation of IAG, the stator current Ist must not be equal to zero. Therefore, the total stator impedance (Zst) must have essentially a zero value.

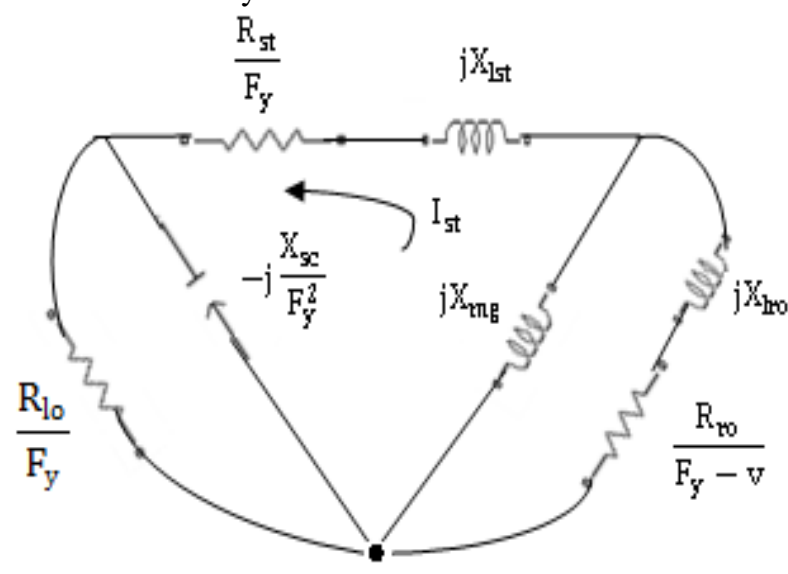

Fig. 2 Equivalent circuit of asynchronous machine with core loss neglected

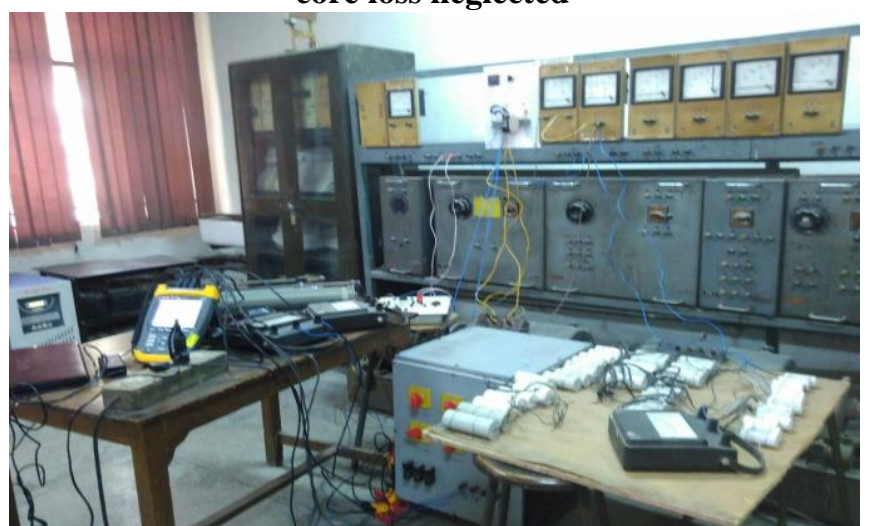

Fig. 3 Photo of the laboratory set-up of the machine us as an IAG

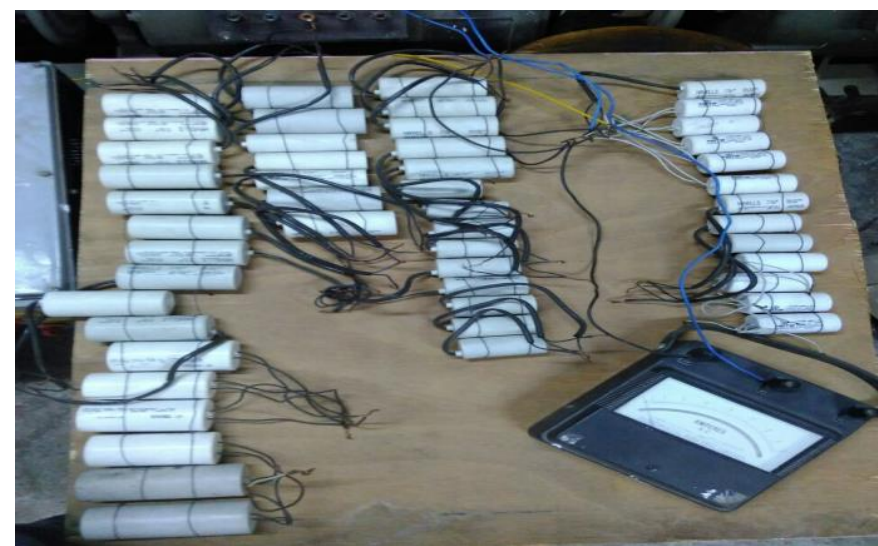

Fig. 4 Photo of the laboratory set-up of the capacitor bank used for IAG

Equating real and imaginary parts of Zst separately equal to zero, the following two nonlinear simultaneous equations with two unknown variables Xmg and Fy. These equations can be easily and conveniently solved using fsolve technique of MATLAB optimization tool box [27].

\section{B. Experimental Results}

Fig. 5 depicts the variation of generator voltage with resistive load for balanced and unbalanced capacitor excitation of $\mathrm{C}=40 \mu \mathrm{F}$. The generator voltage decreases with increase in load in case of both balanced and unbalanced excitation. It is noticed from the result that with balanced excitation, more output power is attained than the unbalanced excitation. At a particular value of load, the generator generates more than the balanced excitation and the winding may be subjected to voltage stress and may affect the insulation of the machine winding. Secondly during unbalanced excitation, machine starts vibrating.

Fig. 6 depicts the variation of speed with resistive load for balanced and unbalanced capacitor excitation of $C=40 \mu \mathrm{F}$. As expected, the speed decreases with increase in load. At a particular value of load the generator speed is slightly more in case of unbalanced excitation than balanced excitation due to more voltage at this load.

Fig. 7 depicts the variation of capacitor current with resistive load for balanced and unbalanced capacitor excitation of $\mathrm{C}=40 \mu \mathrm{F}$.As expected the capacitor current decreases with increase in load. The capacitor current decreases due to decrease in generator voltage with load.

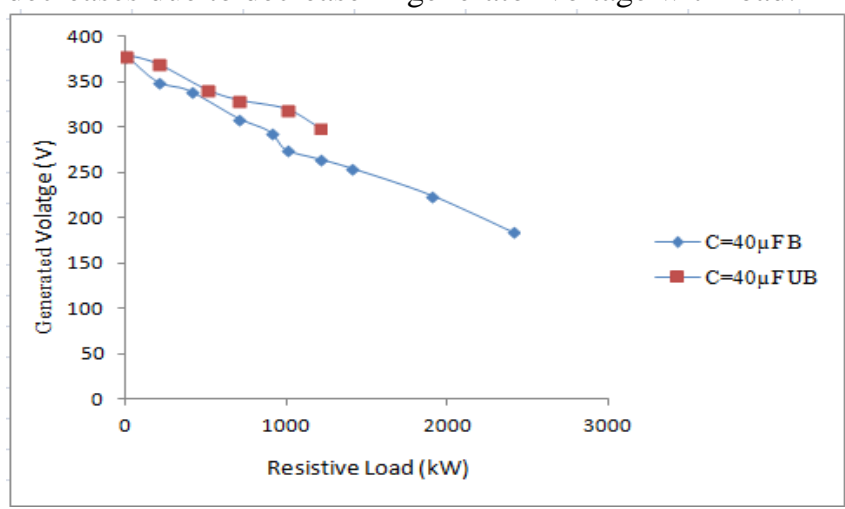

Fig. 5. Generator voltage variation with resistive load

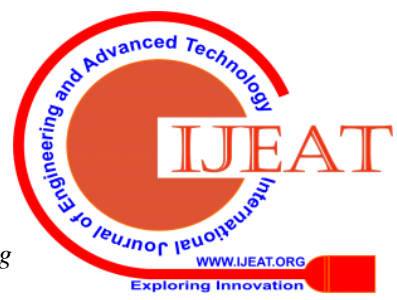




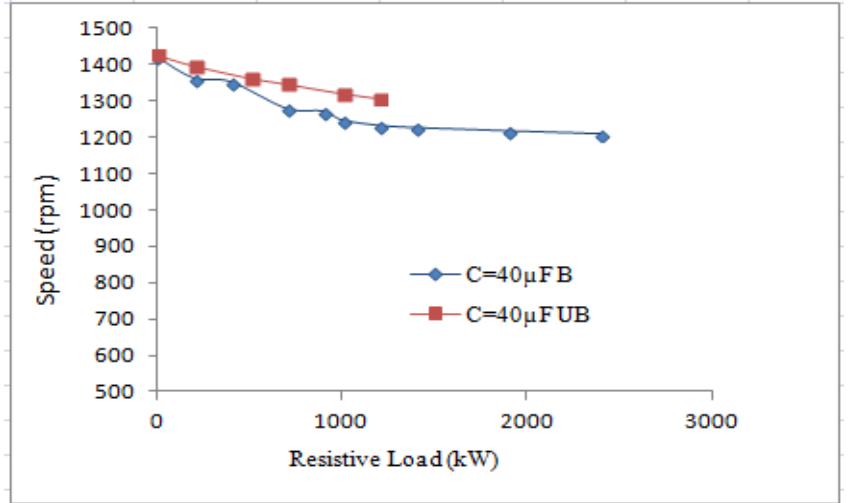

Fig. 6 Load current variation with resistive load

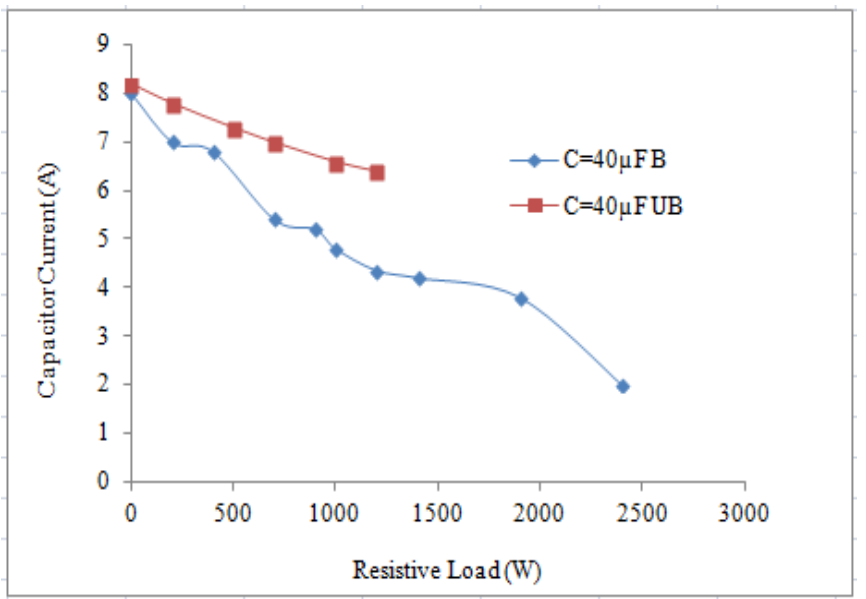

Fig. 7 Capacitor current variation with resistive load

\section{PERFORMANCE ASSESSMENT TECHNIQUES FOR THE 3-PHASE IAG FURNISHING 1-PHASE LOAD EVIEW CRITERIA}

An attempt to analyse the performance of 1-phase SEIG furnishing 1-phase lighting load on a hardware set-up of $1 \mathrm{HP}$ induction machine in the laboratory is made [28]. The experimental study is carried out in order to check the suitability of 1-phase SEIG for feeding lighting loads. This switching circuit provides the guidelines to the design engineers for designing voltage regulation scheme for SEIG. The capacitor switching proves to be economical and can be easily implemented for supplying power in off-grid areas. Such cost effective generating units may be utilised for electrical power generation in remote sites and off- grid areas for meeting lighting load requirement.

A detailed experimental study to carry out to check the feasibility of Self-excited self-regulated single-phase IG for its practical use is discussed [29]. The performance assessment of 1-phase SEIG is carried out at constant speed for maintaining terminal voltage at desired level. The effect of various parameters i.e. speed, load, power factor and shunt and series capacitances on the performance characteristics have been analyzed. It is observed that due to speed drop, the voltage regulation was little bit poorer and its value could be improved either by using a saturable core reactor or by doing speed regulation.

The performance characteristics of 1-phase SEIG subjected to no load and resistive load condition is described [30]. For the performance assessment, the values of frequency $\mathrm{F}$ and magnetizing reactance $\mathrm{Xm}$ are obtained from admittance based equivalent circuit. Upon equating the imaginary part of the total admittance across air gap node equal to zero, the value of $\mathrm{Xm}$ is obtained. The solution of the 9th degree polynomial by Newton Raphson method yields the value of F. By using this known value of $\mathrm{F}, \mathrm{Xm}$ is obtained. With the attained values of F, Xm and Vg of the asynchronous machine, the complete performance of the SEIG is attained using the equivalent circuit. The analytical outcomes are tested and verified experimentally and validate the proposed scheme. This study helps the design engineers in selecting the proper size of capacitor according to the machine rating so that optimum performance and optimum utilization of the machine can be made.

The performance assessment of 1- phase IG corresponding to steady state situation is presented [31]. The excitation capacitor is inserted in one winding (auxiliary winding) and the load is inserted in the second winding (main winding). The application of the symmetrical component theory in the equivalent circuit finally resulted into two non-linear equations having two unknown variables $\mathrm{Xm}$ and $\mathrm{F}$. A numerical technique i.e. Newton Raphson technique is used to evaluate the values of $\mathrm{Xm}$ and $\mathrm{F}$. Based on these analytical values, the complete performance of the machine is determined. The analytical results are validated experimentally.

A method of selecting the value of excitation capacitance to attain optimum excitation of 1-phase SEIG is identified [32]. For performance asesment of SEIG under steady state condition, the values of frequency $\mathrm{F}$ and magnetizing reactance Xm are evaluated using SUMT and Rosenbrock's method of rotating coordinates. After knowing the values of $\mathrm{F}$ and $\mathrm{Xm}$, the complete performance of the SEIG is accomplished using no-load characteristics and the equivalent circuit. With fixed and variable shunt excitation capacitor scheme, the SEIG can be loaded to $150 \%$ rating of the machine provided winding currents should lies within the rated value. With shunt and series excitation capacitor scheme, the SEIG can be loaded safely to $140 \%$ rating of the machine.

The performance assessment of a single-phase SRSEIG based on symmetrical component theory is focussed [33]. A pattern search optimisation method is used to evaluate the value of Xm and $\mathrm{F}$ for the performance assessment purpose. Finally the effect of series capacitance on various aspects i.e. voltage regulation, phase balancing capability, capacitance calculation for perfect phase balance, voltage unbalance factor, output power and efficiency is demonstrated.

The performance assessment of 3-phase SEIG with the asymmetrical connected Xc and load with the aid of symmetrical components is explained [34]. In this paper, a function based on scalar impedance is minimized using pattern search based optimisation method. The search strategies for attaining the optimum value of $\mathrm{Xm}$ and $\mathrm{F}$ for the performance assessment is based on exploratory and pattern moves. Moreover, a scheme for accomplishing almost exact phase balancing based on MSC is implemented in this discussed paper. 
The way of evaluating the optimal value of excitation capacitance required for obtaining maximum power output of three-phase SEIG (star connected) for furnishing 1-phase inductive and capacitive load is discussed [35]. The values of $\mathrm{Xm}$ and $\mathrm{F}$ are attained using Sequential Unconstrained Minimization Technique (SUMT). It is noticed that the voltage related to maximum power output is found to within the defined and acceptable bounds. Also, the voltage regulation is found to be small due to presence of two series connected capacitances. The close association of the experimental and simulated outcomes validates the discussed scheme.

A secant method to obtain the values of $\mathrm{Xm}$ and $\mathrm{F}$ for finding the minimum value of $\mathrm{C}$ for three-phase SEIG furnishing single-phase load is explored [36]. In this paper, the Steinmetz connection is adopted for a 3-phase generator excited by a single capacitor and feeding a 1-phase load. For voltage build or self-excitation phenomenon, the sum of the generator impedance using loop method has been equated to zero. This complex equation is separated into real and imaginary parts and equated individually to zero to attain the value of F and Xc using Secant method for the performance assessment purpose. The various results showing the effect of speed, load impedance and power factor on the excitation is demonstrated. The minimum and maximum values of speed, load impedance and power factor required to sustain self-excitation is provided. An iterative technique is adopted for evaluating the value of excitation capacitance requisite to support terminal voltage under load conditions. The analytical results are validated using an experimental set-up of $2 \mathrm{~kW}$ asynchronous machines.

An optimization technique to evaluate the value of excitation capacitance for the 3-phase SEIG furnishing 1-phase load is discussed [37]. The C-2C configuration is chosen to ensure the existence of self excitation phenomenon and to minimize voltage unbalances in stator voltages. The values of $\mathrm{Xm}$ and $\mathrm{F}$ for the performance assessment are attained using a gradient solver initiated by a sequential generic (GA) is used to minimise a cost function of the sum of equivalent impedances plus the voltage unbalance factor.

The performance of three-phase SEIG with the aid of symmetrical component theory and two-port network is investigated [38]. The unbalanced loads are modelled using the concept of two-port network. The analytical results are verified experimentally on a $0.5 \mathrm{Hp}$ asynchronous machine. Both results are closely related and validate the proposed scheme.

Several phase balancing schemes for a three-phase SEIG furnishing single phase load or single phase power system is focussed [39]. Perfect phase balance is obtained using modified Steinmetz connection. The proposed schemes are based on phase converters consisted of passive circuit elements. Symmetrical component theory is adopted for carrying out performance assessment under steady state and for attaining the perfect phase balanced operation. Experimental investigations are carried out on an asynchronous machine to verify the feasibility of theoretical investigations.

The dynamic equations of the three-phase SEIG furnishing 1-phase resistive load with single capacitor excitation is derived [40]. This paper focussed on three types of stator connection: 1-phase connection, Steinmetz connection I and II. The lower and upper value of excitation capacitance corresponding to no load and load conditions for the three types of stator connections are evaluated using the concept of Eigen value and Eigen value sensitivity. The analytical results achieved using the proposed scheme for the three types of stator connection are validated experimentally on a $1.1 \mathrm{~kW}$ an asynchronous machine.

The symmetrical component theory based steady state performance characteristics of a 3-phase SEIG with a one capacitor excitation and feeding a 1-phase load is presented [41]. For performance assessment, the values of $\mathrm{F}$ and $\mathrm{Xm}$ are evaluated using pattern search method proposed by Hooke's and Jeeve's. Steinmetz connection is used here for feeding 1-phase load. Steinmetz connection with excitation capacitor connected across the lagging phase results into better voltage regulation and better performance characteristics relating to output power, efficiency and voltage unbalance factor. Experimental investigations are performed on asynchronous machine $(2.2 \mathrm{~kW})$ to validate analytical investigations and the proposed scheme.

The symmetrical component theory based steady state performance assessment of 1-phase SRSEIG using a 3-phase asynchronous machine is revealed [42]. For performance assessment, the values of $\mathrm{F}$ and $\mathrm{Xm}$ are evaluated using Hooke's and Jeeve's method (Pattern search method). The Steinmetz connection is used in single phase SRSEIG. This generator improved the voltage regulation, increased power output and provided better phase balance. The close resemblance of the experimental and theoretical outcomes confirmed the validity of the suggested scheme.

The symmetrical component theory based performance assessment of a 3-phase IG feeding 1-phase load using Smith connection (SMIG) is presented [43]. Further, the conditions for achieving the perfect phase balance are derived.

Under perfect phase balance condition, the mathematical expression for line power factor and line current are derived from the phasor diagram. The proposed phase balancing scheme and analytical results are validated experimentally on a $2.2 \mathrm{~kW}$ induction machine. A novel excitation scheme for a three-phase SEIG furnishing single-phase load is suggested [44]. The Smith connection is opted here for excitation capacitor and phase winding connection. This excitation capacitor provided phase balancing in addition to the self excitation phenomenon. For performance assessment, the values of $\mathrm{F}$ and $\mathrm{Xm}$ are evaluated using Pattern search method (Hooke's and Jeeve's). With the help of phasor diagrams, the conditions for achieving perfect phase balance and the value of excitation capacitance is deduced. The proposed scheme resulted into higher efficiency, larger power output and noise free operation of the generator due to perfect phase balance. The theoretical aspects of SMSEIG are validated through experiments on a induction machine of 2.2 $\mathrm{kW}$ The four different schemes for phase balancing for 3-phase IG energised by a 1-phase system is discussed [45]. These four schemes are realized or implemented using phase converters consisting of passive elements only. 
The steady state performance assessment of IG and condition for attaining the perfect phase balance is carried out using symmetrical component theory. The effect of phase balancing on the system power factor, power and its efficiency has been illustrated. The theoretical outcomes are validated experimentally on a $2 \mathrm{~kW}$ induction machine set.

The performance assessment of a 3-phase SEIG (Y-connected) excited by a three capacitor connection is presented [46]. Two series connected capacitors are held across the generator and the remaining capacitor is connected across the 1-phase load.. The complete performance is accessed during the starting of self-excitation phenomenon, load application and perturbation and short circuit load terminals under transient conditions. For performance assessment, the values of $\mathrm{Xc}$ and $\mathrm{F}$ are evaluated using SUMT along with Rosenbrock's method of rotating coordinates. Finally the simulation based results are validated experimentally. Both results showed good resemblance. It is inferred from the outcomes that good voltage regulation, sustained self-excitation phenomenon and sinusoidal nature output voltage and current are achieved using the proposed scheme.

When a 3-phase SEIG feeds unbalanced load then an unbalance in generator voltage and current takes place which finally results into overheating and derating of the machine is revealed or stated [47]. This paper explores a 3-capacitor circuit scheme and evaluates the values of excitation capacitor that balance the 3-phase SEIG system supplying 1-phase load. The 3-capacitor scheme is formed by using one fixed capacitor scheme and two variable capacitor schemes. The fixed capacitor scheme provides the requisite reactive power whereas the two variable capacitor schemes help in balancing the SEIG system feeding 1-phase resistive and inductive load. The two variable capacitor schemes is formed by using two

SVC's, a parallel combination of a fixed capacitor and a TCR. This paper proposed a two port model for evaluating the values of 3 capacitors to balance the SEIG system. The analytical results attained using two port networks are verified experimentally on a $0.375 \mathrm{~kW}$ induction generator.

\section{A. Performance Assessment of 3-Phase IAG Furnishing a 1-Phase Load}

Isolated Asynchronous generators (IAG) may be utilized for furnishing single-phase load [21-30] because of its very simple protection scheme, economical and almost maintenance less operation.

Above $5 \mathrm{HP}$, 3-phase IAG is preferred due to economical advantages over 1 - phase IAG of the same rating. These advantages are low cost and have higher efficiency than the equivalent rating single-phase machine. Hence, it encourages the researchers to use three-phase IAG for furnishing single-phase load [33-46]. To minimize the adverse effects of phase unbalancing, a lot of research has been focused on three-phase IAG furnishing 1-phase load.

The performance of 3-phase SEIG or CEIG feeding unbalanced load and single-phase load is accomplished [48]. The performance equations describing the behavior of the capacitor excited induction generator (CEIG) under unbalanced operating conditions/single-phase load conditions is attained analytically using the concept of symmetrical component theory and the sequence equivalent circuits. The equation representing self-excitation criteria is a non-linear equation having two unknowns (magnetizing reactance and frequency). The solution of this nonlinear equation using fsolve technique results in the saturated value of magnetizing reactance and frequency. Using these evaluated values of magnetizing reactance and frequency, the complete performance equations can be accessed from the sequence equivalent circuits. The simulated results are verified experimentally. The results obtained show good resemblance and proved the authenticity of the described scheme.

\section{B. Experimental Outcomes}

The experimental outcomes have been obtained using different capacitor combinations to achieve the desired voltage regulation under varying load. The three capacitor combinations tested in the laboratory are: $\mathrm{Ca}-\mathrm{Cb}-0$ (two balanced capacitor in and one capacitor out of circuit), Ca-2Cc-Cbf (two balanced capacitor and one fixed capacitor in the circuit), Ca-2Cc (two capacitor connected in 1:2 ratio) are presented in Table.1. With Ca-Cb-0 capacitor connection, the voltage regulation varies from $51.31 \%$ to $26.34 \%$ as the capacitance in the capacitor configuration varies from $40-40$ $-0 \mu \mathrm{F}$ to $80-80-0 \mu \mathrm{F}$.

Table. 1 Different Capacitance values combinations for balanced/ unbalanced/single-phase excitation schemes.

\begin{tabular}{|c|c|c|c|c|}
\hline $\begin{array}{c}\text { IAG and load } \\
\text { combination\#1 } \\
\text { 3-phase IAG for }\end{array}$ & Operating condition & $\begin{array}{c}\text { Excitation } \\
\text { capacitance } \\
\text { Values }\end{array}$ & Load voltages & $\begin{array}{c}\text { Voltage } \\
\text { Regulation }\end{array}$ \\
\hline
\end{tabular}


Performance Assessment Techniques for the 3-Phase IAG

\begin{tabular}{|c|c|c|c|c|}
\hline \multirow[t]{3}{*}{ 3-phase loads } & \multirow[t]{3}{*}{$\begin{array}{l}\text { Distrubed balanced condition or failure of one } \\
\text { capacitor from balanced excitation } \\
\qquad \mathrm{C}_{\mathrm{a}}-\mathrm{C}_{\mathrm{b}}-0\end{array}$} & $\begin{array}{l}\mathrm{C}_{\mathrm{a}}=40 \mu \mathrm{F} \\
\mathrm{C}_{\mathrm{b}}=40 \mu \mathrm{F} \\
\mathrm{C}_{\mathrm{c}}=0 \mu \mathrm{F}\end{array}$ & $\begin{array}{l}\mathrm{V}_{\mathrm{o}}=380 \mathrm{~V} \\
\mathrm{~V}_{\mathrm{f}}=185 \mathrm{~V}\end{array}$ & $51.31 \%$ \\
\hline & & $\begin{array}{l}\mathrm{C}_{\mathrm{a}}=60 \mu \mathrm{F} \\
\mathrm{C}_{\mathrm{b}}=60 \mu \mathrm{F} \\
\mathrm{C}_{\mathrm{c}}=0 \mu \mathrm{F}\end{array}$ & $\begin{array}{l}\mathrm{V}_{\mathrm{o}}=380 \mathrm{~V} \\
\mathrm{~V}_{\mathrm{f}}=230 \mathrm{~V}\end{array}$ & $39.47 \%$ \\
\hline & & $\begin{array}{l}\mathrm{C}_{\mathrm{a}}=80 \mu \mathrm{F} \\
\mathrm{C}_{\mathrm{b}}=80 \mu \mathrm{F} \\
\mathrm{C}_{\mathrm{c}}=0 \mu \mathrm{F}\end{array}$ & $\begin{array}{l}\mathrm{V}_{\mathrm{o}}=380 \mathrm{~V} \\
\mathrm{~V}_{\mathrm{f}}=280 \mathrm{~V}\end{array}$ & $26.31 \%$ \\
\hline \multirow{3}{*}{$\begin{array}{l}\text { IAG and load } \\
\text { combination\#2 } \\
\text { 3-phase IAG for } \\
\text { single-phase loads }\end{array}$} & \multirow[t]{3}{*}{$\begin{array}{c}\mathrm{C}_{\mathrm{a}}-2 \mathrm{C}_{\mathrm{c}}-\mathrm{C}_{\mathrm{bf}} \text { with one fixed capacitor across third } \\
\text { winding }\end{array}$} & $\begin{array}{l}\mathrm{C}_{\mathrm{a}}=20 \mu \mathrm{F} \\
\mathrm{C}_{\mathrm{b}}=30 \mu \mathrm{F} \\
\mathrm{C}_{\mathrm{c}}=60 \mu \mathrm{F}\end{array}$ & $\begin{array}{l}\mathrm{V}_{\mathrm{o}}=237 \mathrm{~V} \\
\mathrm{~V}_{\mathrm{f}}=169 \mathrm{~V}\end{array}$ & $28.69 \%$ \\
\hline & & $\begin{array}{l}\mathrm{C}_{\mathrm{a}}=20 \mu \mathrm{F} \\
\mathrm{C}_{\mathrm{b}}=40 \mu \mathrm{F} \\
\mathrm{C}_{\mathrm{c}}=80 \mu \mathrm{F}\end{array}$ & $\begin{array}{l}\mathrm{V}_{\mathrm{o}}=240 \mathrm{~V} \\
\mathrm{~V}_{\mathrm{f}}=184 \mathrm{~V}\end{array}$ & $23.33 \%$ \\
\hline & & $\begin{array}{l}\mathrm{C}_{\mathrm{a}}=20 \mu \mathrm{F} \\
\mathrm{C}_{\mathrm{b}}=50 \mu \mathrm{F} \\
\mathrm{C}_{\mathrm{c}}=100 \mu \mathrm{F}\end{array}$ & $\begin{array}{l}\mathrm{V}_{\mathrm{o}}=242 \mathrm{~V} \\
\mathrm{~V}_{\mathrm{f}}=200 \mathrm{~V}\end{array}$ & $17.35 \%$ \\
\hline \multirow{3}{*}{$\begin{array}{l}\text { IAG and load } \\
\text { combination\#3 } \\
\text { 3-phase IAG for } \\
\text { 1-phase load with } \\
\text { phase balance }\end{array}$} & \multirow[t]{3}{*}{$\mathrm{C}_{\mathrm{a}}-2 \mathrm{C}_{\mathrm{c}}$} & $\begin{array}{l}C_{a}=30 \mu F \\
C_{c}=60 \mu F\end{array}$ & $\begin{array}{l}V_{\mathrm{o}}=240 \mathrm{~V} \\
\mathrm{~V}_{\mathrm{f}}=224 \mathrm{~V}\end{array}$ & $6.67 \%$ \\
\hline & & $\begin{array}{l}\mathrm{C}_{\mathrm{a}}=40 \mu \mathrm{F} \\
\mathrm{C}_{\mathrm{c}}=80 \mu \mathrm{F}\end{array}$ & $\begin{array}{l}V_{o}=240 V \\
V_{f}=226 V\end{array}$ & $5.83 \%$ \\
\hline & & $\begin{array}{c}C_{\mathrm{a}}=50 \mu \mathrm{F} \\
\mathrm{C}_{\mathrm{c}}=100 \mu \mathrm{F}\end{array}$ & $\begin{array}{l}V_{\mathrm{o}}=240 \mathrm{~V} \\
\mathrm{~V}_{\mathrm{f}}=231 \mathrm{~V}\end{array}$ & $3.75 \%$ \\
\hline
\end{tabular}

With Ca-2Cc-Cbf capacitor connection, the voltage regulation varies from $28.69 \%$ to $17.35 \%$ as the capacitance in the capacitance configuration varies from $20-30-60 \mu \mathrm{F}$ to 20-50-100 $\mu$ F. With Ca-2Cc capacitor connection, the voltage regulation varies from $6.67 \%$ to $3.75 \%$ as the capacitance in the capacitance configuration varies from $30-60 \mu \mathrm{F}$ to $50-100 \mu \mathrm{F}$. It has been observed from the experimental investigations that the value of voltage regulation in case of Ca-2Cc capacitor connection is smaller than the other capacitor

connection schemes and its value is minimum for capacitor combination $50-100 \mu \mathrm{F}$. Hence it is inferred that better voltage regulation is attained in case of $\mathrm{Ca}-2 \mathrm{Cc}$ capacitor connection and the best voltage regulation has been attained for $50-100 \mu \mathrm{F}$. Hence the performance assessment under steady state has been accomplished for 50 - $100 \mu \mathrm{F}$ (Ca-2Cc).

\section{CONCLUSION}

Various techniques regarding the performance assessment of 3-phase IAG subjected to balanced/ unbalanced nature load under steady state and transient state are elaborated along-with advantages and disadvantages. This primary performance assessment needs to be carried out prior to designing of control strategy of controllers for voltage and frequency support. In the prevailing literature, the performance assessment is based on problem identification and formulation using equivalent circuit represented either in admittance or impedance form. The problem formulation finally results into two non-linear type equations. Various researchers have used various numerical techniques (N-R,

secant and Hooke's and Jeeve's method etc.) to solve non-linear equations to evaluate the values of two unknowns for accomplishing the performance of IAG subjected to steady state and transient state. These techniques prove quite efficient and are preferred option for accomplishing the steady state and transient performance of an IAG. But these techniques lack flexibility, involves extraneous calculations in evaluating the various coefficients concerned with higher degree polynomial, model specific, prone to errors and time consuming. Very few papers have discussed the application of fsolve technique and other optimization techniques for performance assessment of IAG.

A MATLAB based routine "fsolve" is also recommended to evaluate the performance under transient and steady state situation of 3-phase IAG furnishing 3-phase and 1-phase load in unattended and unapproachable off-grid located remote communities. It is a built-in user friendly function of MATLAB optimization toolbox and does not requisite any kind of mathematical manipulations; detailed knowledge of MATLAB software and its debugging; handles complexity with flexibility and ease in less computational time.

The IAG voltage and its frequency drop down when subjected to load under transient and steady state. For attaining better performance, the devices must operate at rated voltage, so there realized the need of voltage and frequency controllers for IAG under varying load conditions.

This preliminary study will prove helpful to the researchers for designing various types of voltage and frequency controllers for an IAG.

\section{REFERENCES}

1. B. C Doxey, "Theory and application of the capacitor-excited induction generator", The Engineer, 29, 1963, pp. 893-897.

2. R. Holland, "Appropriate technology-rural electrification in developing countries,” IEE Review, vol. 35, No. 7, July 1989, pp. 251-254.

3. M. G Say, Alternating Current Machines, Wiley, 1976.

4. S. S Murthy, O. P Malik and A. K Tandon, "Analysis of self-excited induction generators,” IEE Proceedings, Part C, vol. 129, No. 6, 1982 pp. 260-265.

5. A K AI Jabri and A. I Alolah, "Limits on the performance of the three phase self-excited induction generators," IEEE Transaction on Energy Conversion, vol. 5, No. 2, June 1990, , pp. 350-356. 
6. N. H Malik and S. E Hague, "Steady state analysis and performance of an isolated self-excited induction generator," IEEE Transaction on Energy Conversion, vol. EC-1, No. 3, 1986, , pp. 134-139.

7. S. P Singh, B. Singh and M. P Jain, "Performance characteristics and optimum utilization of a cage machine as capacitor excited induction generator," IEEE Transaction on Energy Power Conversion, vol.5, No.4, 1990, pp. 679-685.

8. M. H Haque, "A novel method of evaluating performance characteristics of a self-excited induction generator," IEEE Transaction on Energy Conversion, vol. 24, No. 2, 2009, , pp. 358-364.

9. A.H A.L-Bahrani, and N. H Malik, "Steady state analysis and performance characteristics of a three-phase induction generator self-excited with a single capacitor," IEEE Transaction on Energy Conversion, vol. 5, No. 4, Dec 1990, pp. 725-732.

10. M. H Haque and A. L Maswood, "Determination of excitation capacitance of a three-phase self-excited induction generator," IEEE Power and Energy Society General Meeting, 1-6, 2012.

11. S. S Murthy, B. Singh, S. Gupta and B. M Gulati, "General steady- state analysis of three-phase self-excited induction generator feeding three-phase unbalanced load/single-phase load for stand-alone applications," IEE Proceedings - Generation Transmission and Distribution, vol. 150, No.1, 2003, pp. 49-55.

12. A.H A.L-Bahrani and N. H Malik, "Steady-state analysis of parallel operated self-excited induction generators," Proc. IEE, Part C, vol. 140, No.1, 1993, pp. 49-55.

13. A.H A.L-Bahrani and N. H Malik, "Voltage control of parallel operated self-excited induction generators," IEEE Transaction on Energy Conversion, vol. 8, No. 2, June 1993, , pp. 236-242.

14. A. H A.L Bahrani, "Analysis of self-excited induction generators under unbalanced conditions," Electric Machines and Power Systems, vol. 24, Issue. 2, 1996, pp. 117-129.

15. N. H Malik and A. L Bahrani, "Influence of the terminal capacitance on the performance characteristics of self-excited induction generator," Proc. IEE, vol. 137, No. 2, 1990, pp. 168-173.

16. Y.H.A Rahim, "Excitation of isolated three-phase induction generator by a single capacitor," IEE Proc, vol. 140, No. 1, 1993, pp. 44-50.

17. K. S Sandhu and S. K Jain, "Operational aspects of self-excited induction generator using a new model," Electrical Machines and Power Systems, vol. 27, No. 2, 1999, pp. 169-180.

18. T. F Chan, "Analysis of self-excited induction generators using an iterative method," IEEE Transactions on Energy Conversion, vol. 10, No. 3, 1995, pp. 502-507.

19. K. S Sandhu, "Iterative model for the analysis of self-excited induction generators," Electrical Power Components and Systems, vol. 31, No. 10, 2003, pp. 925 - 939 .

20. A. L. Alolah and M. A. Alkanhal, "Optimization based steady state analysis of three-phase self-excited induction generator," IEEE Transaction on Energy Conversion, vol. 15, No.1, 2000, pp. 61-65.

21. D. Joshi, K. S Sandhu, and M. K Soni, "Constant voltage and constant frequency operation of a self-excited induction generators," IEEE Transaction on Energy Conversion, vol. 21, No. 1, 2006, pp. 228-234.

22. T. F Chan, "Analysis of a single phase self-excited induction generator," Electrical Machines and Power Systems, vol. 23, No. 2, 1995, pp. 149-162.

23. T. F Chan, "Self-excited induction generators driven by regulated and unregulated turbines," IEEE Transaction on Energy Conversion, vol. 11, No. 2, June 1996, pp. 338-343.

24. L. Quazene and G. Mcpherson, "Analysis of the isolated induction generator," IEEE Transaction on Power Apparatus and Systems, vol. PAS-102, No. 8, Aug 1983, , pp. 2793-2798.

25. J. L Bhattacharya and J. L Woodward, "Excitation balancing of a self-excited induction generator for maximum power output," IEE Proc., vol. 135, No. 2, 1988, , pp. 88-97.

26. L. Wang and C.H Lee, "Long -shunt and short-shunt connections on dynamic performance of a SEIG feeding an induction motor load," IEEE Transactions on Energy Conversion, vol.15, No. 1, March 2000, pp. 1-7.

27. S. Boora, S.K Agarwal and K. S Sandhu, "Analytical and Experimental Investigations of Shunt Capacitor-Stimulated Induction Generator (SCSIG)," International Journal Series in Engineering Science, vol. 4, 2018, pp.1-25

28. B. Singh, R. B Saxena, S. S Murthy and B. P Singh, "A single-phase self-excited induction generator for lighting loads in remote areas," International Journal on Electrical Engineering Education, vol. 25, , 1988, pp. 269-275

29. S. S Murthy, H. C Rai and A. K Tandon, "A novel self-excited self-regulated single-phase induction generator, Part II: Experimental Investigation," IEEE Trans. Energy Conversion, vol. 8, No. 3, September 1993, pp.383-388.
30. T. F Chan, "Analysis of a single-phase self-excited induction generator," Electrical Machines and Power Systems, vol. 23, Issue.2, 1995. pp. 149-162.

31. Y. H. A Rahim, A.I Alolah and R.I Al-Mudhaiheem, "Performance of single phase induction generators," IEEE Transaction on Energy Conversion, vol. 8, No. 3, September 1993, pp. 389-395.

32. B. Singh and L. B Shilpkar, "Steady-state analysis of single-phase self-excited induction generator," IEE Proceeding of Generation, Transmission, and Distribution, vol. 146, No. 5, September 1999, pp. 421-427.

33. T. F Chan and L. L Lai, "Steady-state analysis and performance of a single-phase self-regulated self-excited induction generator," IEE Proceeding of Generation, Transmission and Distribution, vol. 149, No. 2, March 2002, pp. 233-241.

34. T. F Chan and L. L Lai, "Steady-state analysis and performance of a stand-alone three-phase induction generator with asymmetrically connected load impedances and excitation capacitances," IEEE Transaction on Energy Conversion, vol. 16, No.4, December 2001, pp. 327-333,

35. S. N Mahto, S. P Singh and M. P Sharma, "Capacitors required for maximum power of a self-excited single-phase induction generator using a three-phase machine," IEEE Transaction on Energy Conversion, vol. 23, No. 2, June 2008., pp. 372-381,

36. T. F Chan, L. L Lai, "Capacitance requirements of a three-phase induction generator self-excited with a single capacitance and supplying a single-phase load," IEEE Transaction on Energy Conversion, vol.17, No. 1, March 2002.

37. A. I Alolah and M. A Alkanhal, "Excitation requirements of three phase self excited induction generator under single phase loading with minimum unbalance," in Proceedings of IEEE Power Engineering Society Winter Meeting, Singapore, Jan. 23-27, 2000, , pp. 257-259.

38. Y. J Wang and S.Y Huang, "Analysis of a stand-alone three-phase self-excited induction generator with unbalanced load using a two-port network model," IET Electrical Power Application, vol. 3, Issue.5, January 2009, pp. 445-452.

39. T. F Chan and L. L Lai, "Phase balancing for a self-excited induction generator," in Proceedings of International Conference on Electric Utility Deregulation, Restructuring and Power Technologies, London, UK, April 2000, , pp. 602-607

40. L. Wang and C. M Cheng, "Excitation capacitance required for an isolated three-phase induction generator under single-phasing mode of operation," in Proceedings of International Conference of Power Engineering Society Winter Meeting, Columbus, USA, pp. 1403-1407, 2001.

41. T. F Chan, "Performance analysis of a three-phase induction generator self-excited with a single capacitance," IEEE Trans. on Energy Conversion, vol.14, No.4, December 1999, pp. 894-900.

42. T. F Chan and L. L Lai, "A novel single-phase self-regulated self-excited induction generator using a three-phase machine," IEEE Trans. on Energy Conversion, vol.16, No. 2, June 2001, pp. 204-208.

43. T. F Chan and L. L Lai, "Single-phase operation of a three-phase induction generator with the Smith connection," IEEE Transaction on Energy Conversion, vol. 17, No. 1, 2002, , pp. 47-54.

44. T. F Chan and L. L Lai, "A novel excitation scheme for a stand-alone three-phase induction generator supplying single-phase loads," IEEE Trans. Energy Conversion, vol. 19, No.1, March 2004, pp. 136-142.

45. T. F Chan and L. L Lai, "Phase balancing for an induction generator operating on a single phase power system," IEEE Conference, 2000, pp 167-170.

46. S. N Mahato, M. P Sharma and S. P Singh, "Transient performance of a single-phase self-regulated self-excited induction generator using a three-phase machine," Electric Power System Research,, 2007, pp. 839-850.

47. Y. J Wang and M. H Lee, "A method for balancing a single-phase loaded three-phase induction generator," Energies, 2012, pp. 3534-3549.

48. S. Boora, S.K Agarwal and K. S Sandhu, "Optimization Based Performance Assessment of CEIG for Rural Sites," Science Direct Procedia Computer Science, Elsevier, Vol.132, 2018, pp. 849-862.

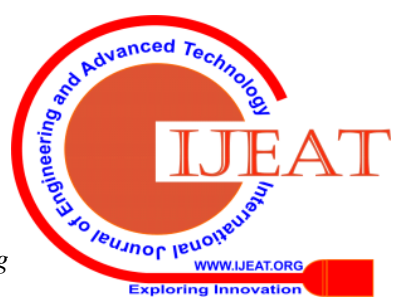




\section{Performance Assessment Techniques for the 3-Phase IAG}

\section{AUTHORS PROFILE}

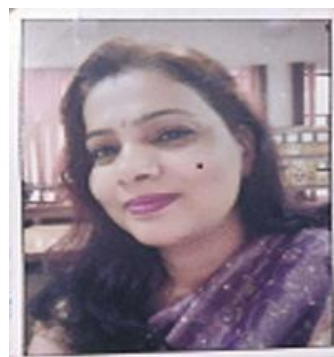

Dr. Shakuntla Boora, received the B.E degree (Electrical Engineering) from MDU Rohtak (Haryana) in 1997 and M. E degree

(Power Systems) from Punjab University in 2004 and Ph.D degree (Electrical) from JCBUST, YMCA, Faridabad in 2019. Since 2007, She is the part of JCB University of Science \& Technology, YMCA as Assistant professor in the Department of Electrical Engineering. She has 25 international and national publications in the area of electrical machines and induction generators. 